Article

\title{
Decoupling Economic Growth and Environmental Degradation: Reviewing Progress to Date in the Small Island State of Malta
}

\author{
Elisabeth Conrad * and Louis F. Cassar \\ Institute of Earth Systems, University of Malta, Msida MSD 2080, Malta; \\ E-Mail: louis.f.cassar@um.edu.mt \\ * Author to whom correspondence should be addressed; E-Mail: elisabeth.conrad@um.edu.mt; \\ Tel.: +356-2340-2873.
}

External Editor: Stephen Morse

Received: 29 May 2014; in revised form: 9 September 2014 / Accepted: 12 September 2014 /

Published: 29 September 2014

\begin{abstract}
This paper considers the challenge of decoupling economic growth from environmental degradation; in contrast to several large-scale cross-country analyses that focus on limited indicators of environmental degradation, we analyze in some depth the experience of a single small-scale island state setting (Malta). We use available statistical data to derive decoupling factors, in order to consider the extent to which decoupling has been achieved in four sectors: (i) energy intensity, climate change, and air quality; (ii) water; (iii) waste; and (iv) land. Results indicate relative decoupling between economic growth and several indicators considered, and to a lesser extent, relative decoupling between population growth and the same indicators of environmental pressure. Absolute decoupling has been achieved in at least one instance but there has been no decoupling of land development from either economic or population growth. Land use and population thus appear to be notable sources of pressure. The results suggest that decoupling analyses that present environmental degradation in terms of single variables (e.g., carbon emissions) may misrepresent somewhat the state of the environment at local level. Furthermore, the study highlights the need for methodologies that factor in the "embedding" of small-scale settings within much larger trade networks, for a more accurate estimation of environmental impact, and points to some limitations of solely quantitative analyses of environment-ecology relationships.
\end{abstract}

Keywords: decoupling; small island state; Malta 


\section{Introduction}

An important aspect of the environmental management literature considers the strength and nature of the relationship between economic development and environmental degradation, more specifically whether the former can feasibly be achieved without the latter. Some research has supported the existence of an Environmental Kuznets Curve (EKC), according to which environmental degradation increases up to a point as economies grow but then declines with further affluence [1-5]; however, a substantial body of research has cast doubts on whether countries can truly "grow" their way out of environmental problems [6-10]. As a result, the conventional economic growth paradigm is being challenged from multiple sources, with critics arguing that not only are we in danger of exceeding planetary boundaries $[11,12]$, but that unrestrained growth is also a root cause of unsustainability and contributes to political disaffection, social inequality, and loss of quality of life [13,14]. As a result, scholars and activists have argued for the need to separate economic and social well-being from the use of biophysical resources, through eco-economic decoupling or dematerialization [15-18]. Two separate decoupling strands are recognized-resource decoupling and impact decoupling. The former refers to reducing the rate of use of (primary) resources per unit of economic activity, while impact decoupling requires increasing economic output while decreasing corresponding environmental impacts [19]. Haberl et al. [20] identify three distinct decoupling patterns: (i) no decoupling, i.e., material throughput increasing faster or as fast as Gross Domestic Product (GDP); (ii) relative decoupling, where an increase in resource demand/environmental impact persists, but where the proportion of this resource demand/environmental impact per unit of GDP declines; and (iii) absolute decoupling, where resource demand/impact decreases even as GDP continues to grow.

There has been much skepticism concerning the likelihood or feasibility of achieving decoupled economies [21]. A cross-national study found that economic development is more tightly linked with greenhouse gas emissions than it is with life expectancy [22], while a 2011 global review intended to scope the challenges of decoupling concluded that while resource and impact decoupling are taking place, these are occurring "at a rate that is insufficient to meet the demands of an equitable and sustainable society" ([19], p. 74). One proposed means of separating economic progress from environmental degradation focuses on enhancing the efficiency of resource use (or eco-efficiency) (e.g., [23-25]); however, the technological developments associated with eco-efficiency have been shown to be subject to rebound effects (such as the Jevons and Paperless Office Paradoxes [26,27]), with increased efficiency leading to increased consumption and consequently with any environmental benefit being neutralized or limited at best [28,29]. Indeed, several studies have concluded that notwithstanding more efficient resource use, consumption continues to rise [19,30]. As a result, other structural means are being proposed for mitigating environmental impact, such as bolstering the growth of the services sector, and reducing working hours [21]; despite their potential, neither of these, however, has yet resulted in tangible large-scale reductions in environmental impact [9]. Given this lack of substantial progress to date, there has been increasing questioning of the very feasibility of sustained economic growth, with a body of arguments building on long-established literature (e.g., [31-33]) making the case for steady-state (e.g., [34]), a-growth (i.e., conceptually indifferent about growth) (e.g., [35]), or de-growth (e.g., [36,37]) economies, the latter referring broadly to a socially sustainable and equitable reduction of a society's throughput, at least within the affluent context of the developed world. 
The vast majority of recent research in the field of decoupling has examined macro-scale relationships, with a predominance of global reviews, or of cross-country comparisons (especially between developed and developing countries) (e.g., [38-41]). Similarly, environmental degradation has been considered mostly in terms of issues of global concern, most notably climate change, with the variable used to measure environmental degradation commonly being carbon dioxide/other greenhouse gas emissions (e.g., [38,42]); a more limited subset of studies has also considered fossil fuel use, extraction and use of other natural resources, and/or composite measures (such as ecological or planetary footprints). At smaller scales, some national analyses of decoupling have been conducted (e.g., [43,44]). However, there does not yet appear to have been much research that focuses specifically on "small" contexts, such as that of the individual city or of small island states. A strong case can be made for considering the environment-economy relationship in the latter separately from that represented by global or national reviews. First, there is a general agreement that small island states represent a distinct reality, because restricted space inevitably requires that social, political, and economic units exist at a size below those considered normal for modern states and economies [45]. This in turn leads to economic patterns of development that may be distinctly different from those that characterize "mainland" economies [46], suggesting the possibility of different decoupling pathways. Second, the environmental challenges of many small island states are substantial, either in terms of their ability to provide natural resources, or to absorb waste and pollution, or to deal with the manifestations of global change (e.g., [47-50]). This in turn means that the impacts of environmental degradation are experienced differently than they would be within a larger territory. While we recognize that there is a spectrum of small island states, from those that are facing significant environmental threats (such as pollution or biodiversity loss), to those that have managed to safeguard their natural environments (often through designation of protected areas) [45], it is nonetheless fair to say that all such island states have a greater degree of vulnerability to environmental impact simply by virtue of their small size, which enhances environmental vulnerability and limits development alternatives. Third, the above-mentioned particularities of small islands have been shown to often lead to a high degree of innovation and to remarkable resilience, both of which are features that can be considered critical for achieving any form of sustainable "green economy". The experiences of small island states can thus provide useful insights for alternative growth paradigms, with these possibly also being relevant to the experience of cities. A 2011 UNEP study of decoupling specifically noted the important role of the latter, highlighting the following as a key challenge for decoupling research: how can cities best become the spaces where ingenuity, resources and communities come together to generate practical decoupling in the way cities produce and consume? We argue that an analysis of small island states, some of which may be considered to be "microcosms" of the city environment, may provide useful pointers for answering this question.

On this basis, this paper examines a small island state economy-environment relationship, using the Mediterranean island of Malta as a case study. We do not focus on a single environmental indicator, but examine the relationship between changes in the country's Gross Domestic Product (GDP) and population on the one hand, and changes in various environmental indicators, on the other, with a view to understanding the spectrum of environmental impacts, to investigate the strength of linkages between environment and economy, and to estimate the nature and extent of decoupling that has occurred, if any. Section 2 outlines the methods and data sources used, together with related 
limitations, and provides an overview of the study area. In Section 3, we present and discuss the results obtained, with Section 4 outlining the main conclusions of this work.

\section{Experimental}

\subsection{Method}

While various methodologies have been developed for measuring decoupling (e.g., [51,52]), this study adopted the methodology outlined by the OECD in its report entitled Indicators to measure decoupling of environmental pressure from economic growth [53]. This methodology focuses on describing the relationship between the first two elements of the Driving Force-Pressure-State-Impact-Response (DPSIR) framework, i.e., the level of change in the driving force as compared to the level of change in the corresponding environmental pressure. (Malta is not an OECD member and was thus not included in the OECD study). The method, while relatively simple, has the key advantage of being easily adaptable; it is also not overly onerous in terms of its data requirements. These were key considerations for this case study analysis, as the availability of consistent and comparable time-series data for several environmental variables was limited. For the same reasons of data unavailability, this study does not measure all 31 decoupling indicators identified in the OECD study. It instead provides indicative measurements of selected economy-wide indicators from the latter, within the categories of climate change, air pollution, waste management, and use of natural resources (water), and with adaptation of the methodology for measurement of additional indicators considered to be of more direct relevance to the study area context.

The methodology quantifies the ratio between driving force and environmental pressure, as per Equation (1) below.

$$
\text { Ratio }=\frac{(E P / D r F)_{\text {end of period }}}{(E P / D r F)_{\text {start of period }}}
$$

where $\mathrm{EP}=$ environmental pressure and $\mathrm{DrF}=$ driving force.

The decoupling ratio (DR) is in turn used to derive a Decoupling Factor (DF) (Equation (2), which has a negative or zero value in the absence of decoupling and a positive value if decoupling has occurred. Its theoretical maximum value is 1, which would indicate an EP of zero, in an ideal best-case scenario. The DF does not clearly indicate whether decoupling is absolute or relative; however, this can be deduced based on the growth rate of the EP - decoupling is absolute when the EP growth rate is negative or zero (i.e., declining pressure on the environment); it is positive when the EP growth rate is positive but lower than that of the DrF.

$$
\text { Decoupling factor }=1-(\text { Decoupling ratio })
$$

Two DrFs were considered in this analysis - Gross Domestic Product (measured in nominal terms, as per the harmonized ESA95 methodology) and total resident population. Relevant data for these parameters was obtained from the National Statistics Office (NSO) of Malta. Data for EPs is somewhat more disparate and was obtained from a variety of sources, including publications of the same NSO and of environmental/resource management agencies in the country; sources are indicated in the relevant sections below. The years for which data was available varied depending on the environmental parameter in question; for this reason, a separate time series is defined for each indicator in the analysis below. 
We recognize that various sophisticated methods for measuring decoupling have been developed in recent years, including approaches that make use of multivariate panel analysis statistical techniques, and variants of the IPAT mathematical identity developed by Ehrlich and Holdren [54], including STIRPAT [55] and ImPACT [56]. The limitations of using decoupling factors are likewise recognized, including (i) the fact that the absolute level of a variable may be more important than its relation to GDP or population; (ii) their limited suitability for measuring renewable resources; (iii) their limited capacity to consider international cooperation and exchanges; and (iv) their potential failure to reflect complex relationships between DrFs and EPs [57]. DFs are for this reason not suitable as a basis for measuring sustainability or for selecting policy tools; however, they remain very valid for the purpose of assessing how successful individual countries are at reducing pressures on the environment, and indeed may be superior to other techniques for this purpose [57]. For this reason, their use is considered reasonable within this study, particularly given additional data limitations. Indeed, it should be noted that lack of time-series data allowed only a partial assessment of relevant case study EPs. This is a frequently-encountered limitation in such work and was similarly noted in the broader-scale OECD review; indeed, of the 31 indicators identified in the latter, only 10 were considered to be conceptually sound, largely due to statistical gaps limiting the robustness of the remainder of the suite [53]. The results discussed below should therefore be considered as indicative, reflecting several important EPs but also omitting other significant ones for which data was unavailable.

\subsection{Study Area}

Malta achieved the status of a small island state upon acquiring independence from the United Kingdom in 1964, with a republic declared ten years later. The country has a population of 421,400 individuals, resulting in substantial density for the islands' size. Under British rule, Malta sustained thriving maritime industries, particularly in its harbor regions, but with the departure of British forces from the country, an alternative economic revenue-generator was needed, with tourism, and to a lesser degree manufacturing, identified as such; tourism remains a key economic sector to date, with tourist arrivals per annum generally exceeding one million. Numerous strategic initiatives were implemented through the 1960s, 1970s and 1980s with the aim of establishing the country on a firm economic foothold; however, it was not until the early 1990s that a robust legal framework for spatial planning and environmental management was established, the former reinforced through a Structure Plan of policies to regulate future land-use development in Malta. Malta's accession to the European Union in 2004 served to further strengthen the legal natural resource management structure, with various efforts made to bring the situation in Malta in line with that of the European mainland. Notwithstanding, economic policies have continued to be pursued largely independently of environmental protection ones, with few tangible efforts made to integrate the two, despite (largely token) discussions of the need for sustainable development. At present, Malta's economy is dominated by a variety of service and manufacturing industries, with particularly marked growth in financial services and gaming sectors over recent years. Primary industries make a very limited contribution to the country's GDP of less than $2 \%$, even if agriculture remains the country's largest land-user. Based on Gross National Income (GNI) per capita, and as per World Bank criteria, the country is considered to be high income. 


\section{Results \& Discussion}

\subsection{Energy Intensity, Climate Change and Air Quality}

Malta obtains the vast majority of its energy from imported fossil fuels [58], with the main sectors of consumption being power generation for both domestic and industrial uses, and transport. Electricity has been produced primarily using fuel oil, although coal was concurrently in use until 1995 [27]. In recent years, increasing emphasis has been placed on switching to a cleaner gas supply, with current plans to convert the country's main oil-fuelled power station to run on gas. Power generation through renewables remains limited, with Malta lagging far behind the national target of $10 \%$ energy generation from renewables by 2020 [59]. The strongest potential for renewable energy generation would appear to lie in solar technology, with the Islands benefiting from substantial hours of sunlight [60]. The potential for offshore wind energy generation has also been explored but no projects have been implemented to date.

The transportation sector is strongly influenced by very high levels of car ownership (over 318,000 licensed vehicles within a total land area of $316 \mathrm{~km}^{2}$ ), amongst the highest in the world; this is at least in part attributable to a poor public transport network, notwithstanding largely unsuccessful attempts to improve the latter in recent years. Related pollutants include $\mathrm{CO}, \mathrm{NO}_{\mathrm{x}}, \mathrm{VOCs}$, ozone, and particulate matter, with arising environmental health concerns, particularly due to a high prevalence of respiratory ailments in the country [61].

\subsubsection{Energy Production per Unit of GDP and per Capita}

As noted above, the ratio between energy and GDP is one of the most widely used indicators for measuring the decoupling effect. For this study, we used available NSO data for energy production in Malta over the period 2003-2012 [62].

Over these years, energy consumption increased overall by $1.48 \%$ but with fluctuations on an annual basis and consequently with no clear medium- to long-term trend; nominal GDP at market prices increased by $49 \%$ over the same period (Figure 1a), while the resident population of the Maltese Islands increased by 5\% (Figure 1b). When considering changes between start and end of the analysis period, the DF for energy production per unit of GDP is positive (0.32), suggesting that some degree of relative decoupling has occurred between these two variables. However, on a year-by-year basis, the DF varies from -0.1 (with negative values in 2009 and 2012) to a maximum positive value of 0.14 . The DF for energy per capita is also positive, although by a small margin (0.04), and with several negative values for inter-annual differences, suggesting somewhat limited relative decoupling.

\subsubsection{Greenhouse Gas (GHG) Emissions per Unit of GDP and per Capita}

GHG emissions originate from various sectors of the economy but most notably from energy production and transport. This indicator was included in the original OECD suite and similar measures of GHG decoupling have been developed by other authors (e.g., [63,64]). Relevant DFs were compiled for Malta using data covering the period 1995-2012, drawn from the country's 2013 GHG inventory for submission under the United Nations Convention on Climate Change [65]. 
Figure 1. (a) Changes in energy production vs. Gross Domestic Product (GDP) changes (2003-2012) (top); (b) changes in energy production vs. population changes (2003-2012).

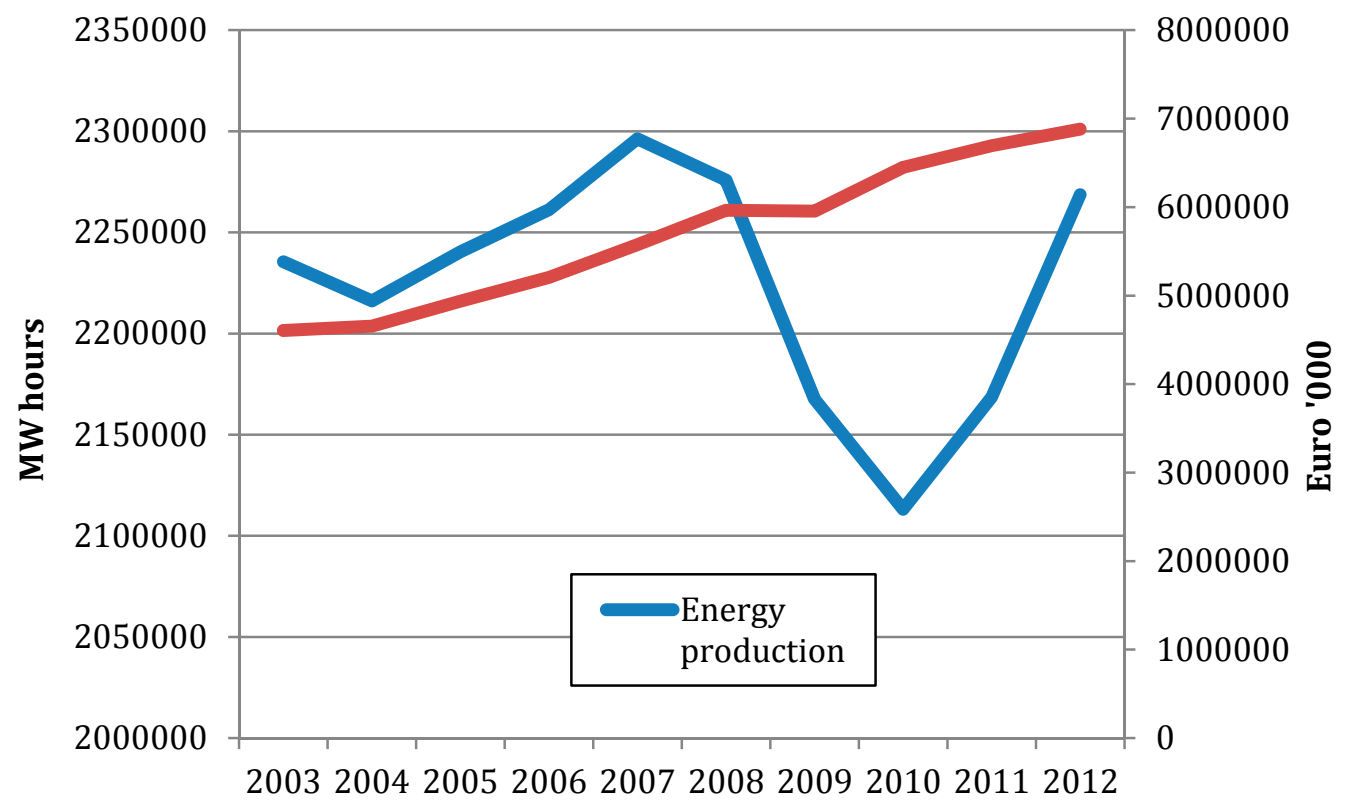

(a)

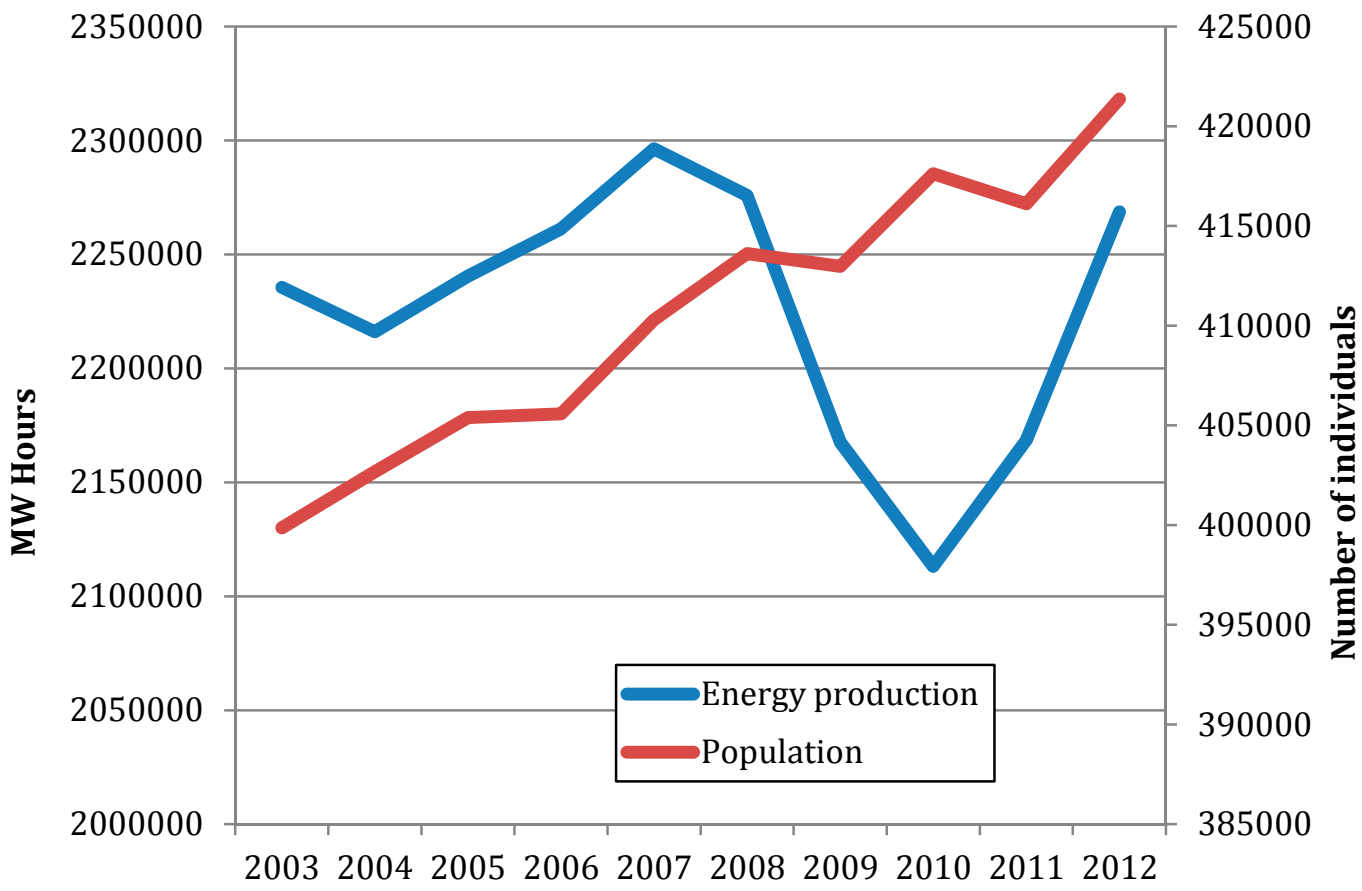

(b)

Figure 2a highlights the significant contribution of $\mathrm{CO}_{2}$ emissions to total net emissions, and the close way in which these variables mirror GDP increases. Nevertheless, some degree of relative decoupling appears to have taken place over the period of analysis, with overall positive DFs for net $\mathrm{CO}_{2}$ emissions per unit GDP (0.45) and for total net GHG emissions per unit GDP (0.42); indeed, while nominal GDP more than doubled over the period of analysis, total emissions increased by $28 \%$. This is not the case for emissions per capita (Figure 2b), with $\mathrm{CO}_{2}, \mathrm{CH}_{4}$, and total emissions all having negative overall DF values $(-0.1,-0.5$, and -0.16 , respectively). In this case, the increase in total emissions surpasses the growth rate of the population $(10 \%)$ over the period in question. The results 
obtained here are broadly similar to those obtained in the OECD study, which likewise recorded a general trend of relative decoupling of GHG emissions from economic growth across OECD countries, but a much less pronounced degree of decoupling per capita [53].

Figure 2. (a) Changes in $\mathrm{CO}_{2}$ and total net emissions vs. GDP (1995-2011) (top); (b) changes in $\mathrm{CO}_{2}$ and total net emissions vs. population changes (1995-2011); the data takes into account emissions and removals by Land Use, Land-Use Change and Forestry (LULUCF) sectors.

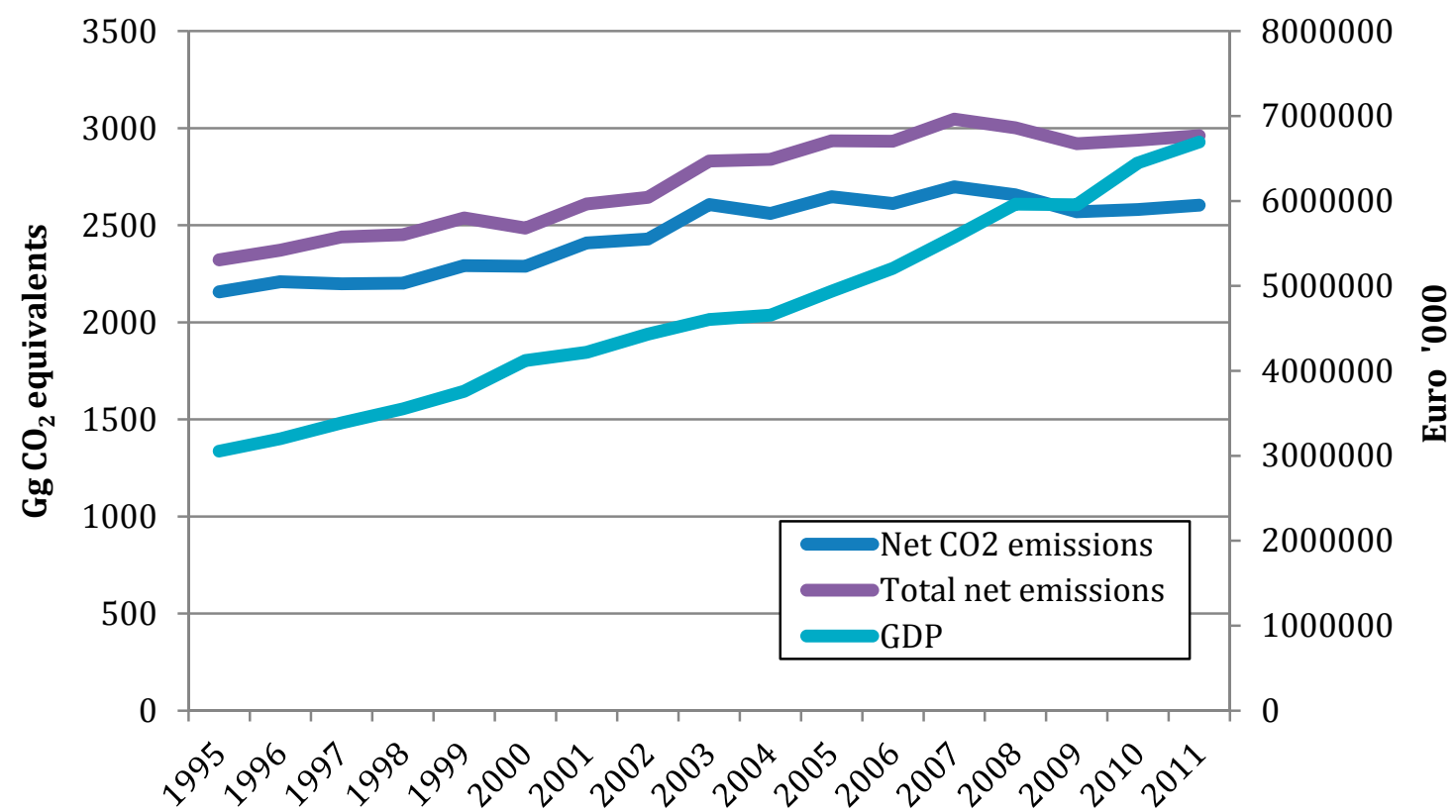

(a)

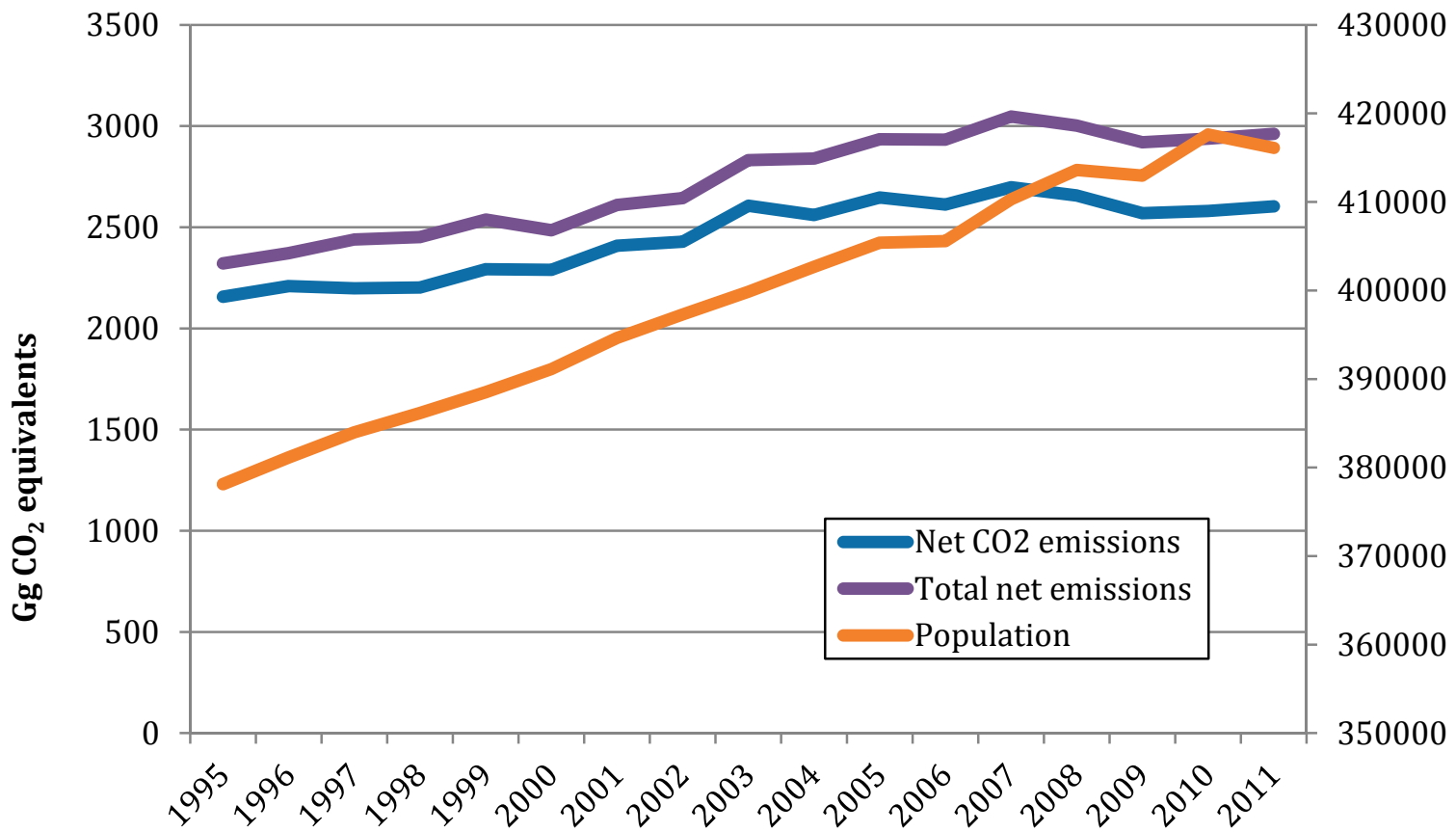

(b) 


\subsection{3. $\mathrm{NO}_{\mathrm{x}}$ Emissions per Unit of GDP and per Capita}

While $\mathrm{NO}_{\mathrm{x}}$ and $\mathrm{SO}_{2}$ contribute indirectly to GHG emissions, these are also of concern as air pollutants originating largely from road transport in the former case, and from stationary combustion facilities and from the use of high sulphur content-oil in diesel engines in the latter case. Both pollutants are considered to contribute to respiratory distress and to diminished urban air quality. Although these pollutants could thus be considered under the broader category of GHGs, they are considered to be of particular significance as air pollutants within the Maltese context, and are therefore considered separately here. The OECD study also included total $\mathrm{NO}_{\mathrm{x}}$ and $\mathrm{SO}_{\mathrm{x}}$ as separate air quality indicators. Relevant data was obtained from the same Greenhouse Gas Inventory cited above [65], over the period of analysis 1995-2011.

Overall, DFs over this time span were positive for emissions per unit GDP (0.54 for $\mathrm{NO}_{\mathrm{x}}$ and 0.87 for $\mathrm{SO}_{2}$ ) and to a lesser degree, for emissions per capita ( 0.09 for $\mathrm{NO}_{\mathrm{x}}$ and 0.74 for $\mathrm{SO}_{2}$ ), suggesting that decoupling has occurred. $\mathrm{NO}_{\mathrm{x}}$ emissions increased marginally over the 11 -year period (by $0.23 \%$ ) while $\mathrm{SO}_{2}$ emissions decreased by over $71 \%$ (Figure 3 ). In the meantime, positive growth was recorded for both GDP and population. This would appear to indicate absolute decoupling from economic growth occurring in the case of $\mathrm{SO}_{2}$ and strong relative decoupling in the case of $\mathrm{NO}_{\mathrm{x}}$. The OECD study [26] recorded absolute decoupling of $\mathrm{NO}_{\mathrm{x}}$ emissions in Europe and relative decoupling in Pacific and North American regions, attributing progress achieved to the use of better emission control technology in combustion plants and to the use of catalytic converters in vehicles. While both of these mitigation measures are relevant to Malta, progress in the country over the period of analysis appears to have been slower by comparison. However, the $\mathrm{DF}$ for $\mathrm{SO}_{2}$ emissions is indicative of stronger performance; absolute decoupling of $\mathrm{SO}_{\mathrm{x}}$ emissions from economic growth was likewise recorded in all OECD regions [53].

\subsection{Water}

Water is a significant concern in the Maltese Islands, with the country classified as one of the top ten water scarce countries worldwide [66,67]. The country has no exploitable surface waters and is limited to groundwater resources and to water produced via desalination technology (reverse osmosis); the latter, however, has significant energy requirements, consuming 3.7\% of electricity produced in Malta [68]. Of all countries in the Mediterranean Basin, Malta has the highest Water Competitive Index (indicative of the ratio between number of inhabitants and volume of freshwater, and thus of the degree of competition for water resources), as well as being highly dependent on virtual water through imported goods [69].

The two indicators considered below use the described methodology but thus focus on water production and abstraction in Malta, rather than on the water quality-related EPs highlighted in the OECD report (the latter being (i) population not connected to sewage treatment plants and (ii) $\mathrm{N}$ and $\mathrm{P}$ discharges from households). Water quality issues were not addressed for reasons of inadequate data, even if these are highly pertinent. Nitrate pollution, for example, is known to be a significant issue in Malta, likely related to a high gross nitrogen balance resulting from extensive use of chemical inputs in agriculture. However, available data is so far limited to single studies and an assessment of change is therefore not possible. 
Figure 3. (a) Changes in $\mathrm{NO}_{\mathrm{x}}$ and $\mathrm{SO}_{2}$ emissions vs. GDP changes (1995-2011) (top); (b) changes in $\mathrm{NO}_{\mathrm{x}}$ and $\mathrm{SO}_{2}$ emissions vs. population changes (1995-2011).

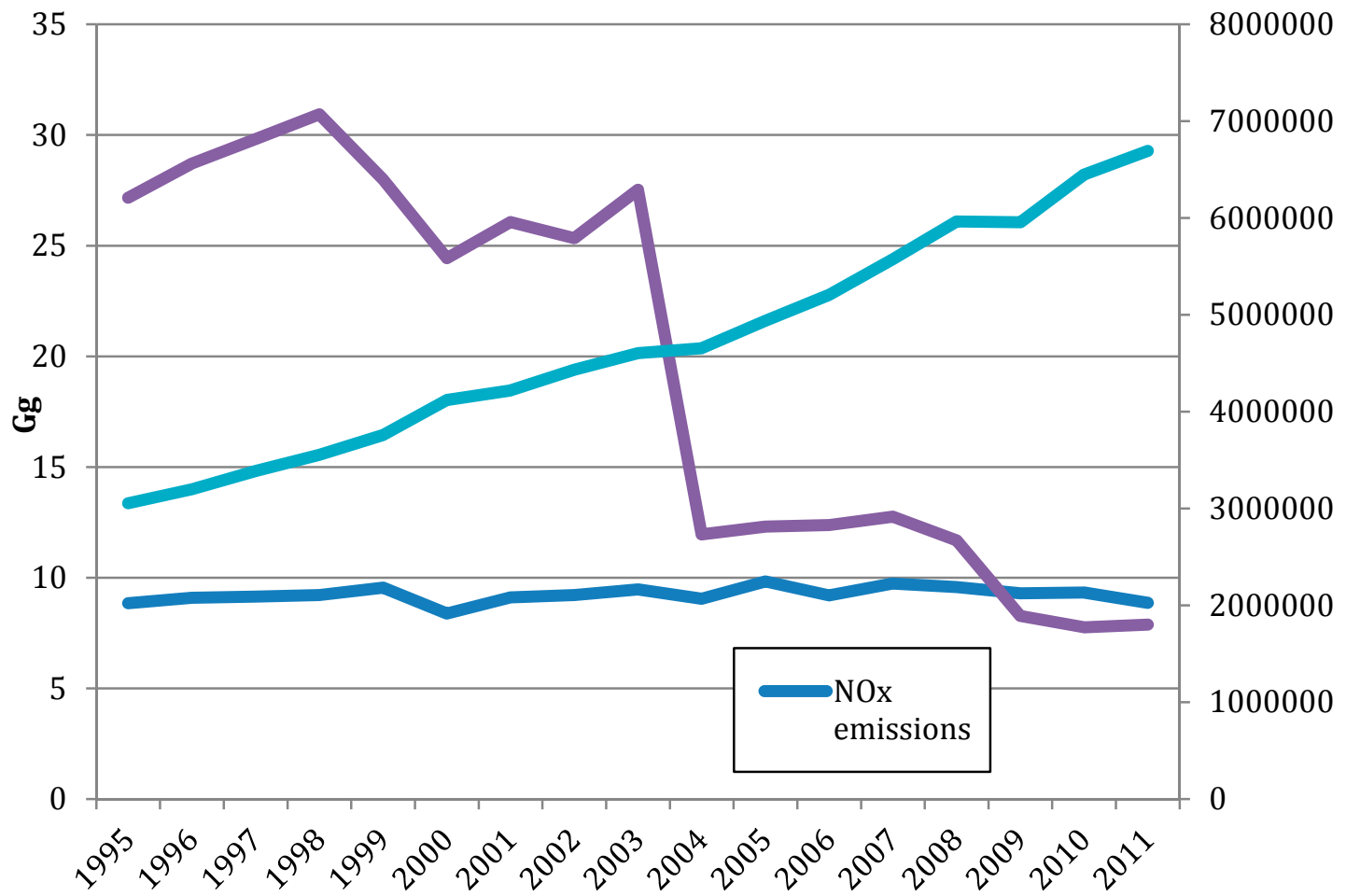

(a)

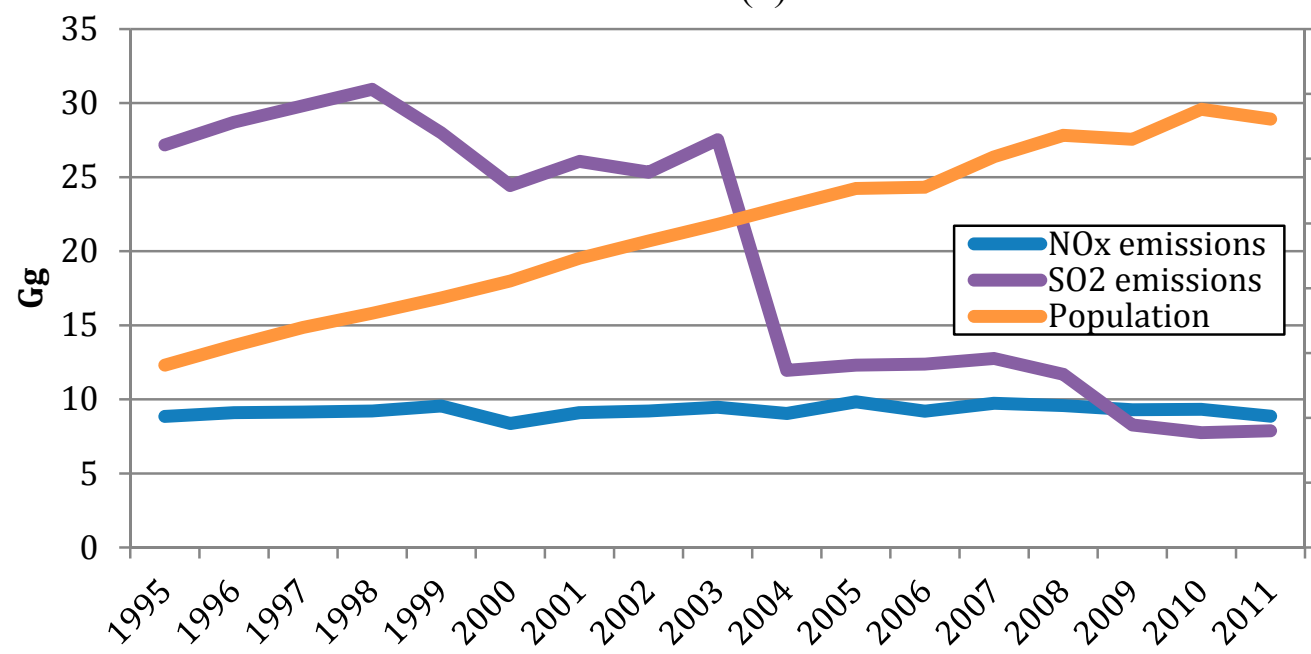

(b)

\subsubsection{Groundwater Abstraction per Unit of GDP and per Capita}

This study used relevant NSO data for groundwater production for 1995-2012 [70]. While both GDP and population increased over this period, groundwater abstraction rates decreased by $34 \%$, indicating absolute decoupling (Figure 4). DF values were positive in all years (with the exception of the 1995-1996 interval) and the relevant overall DF per unit of GDP is 0.71. The corresponding DF per capita is also positive, although lower (0.41). The successful decoupling of groundwater abstraction from GDP may be related to the growth of economic sectors that are not water-dependent (e.g., the gaming sector discussed above). However, it should be noted that widespread illegal groundwater 
abstraction is also widely assumed to take place, with this not reflected in the official data used; however, since the majority of this abstraction is assumed to be for agricultural purposes, and since this sector contributes only marginally to GDP, the inclusion of this data is not expected to alter the overall trend showing decoupling from economic growth. It should also be noted that decoupling per capita does not account for the substantial tourist populations which frequent the Islands on an annual basis, and whose water consumption patterns could be assumed to be different.

Figure 4. (a) Changes in groundwater production vs. GDP changes (1995-2012) (top); (b) changes in groundwater production vs. population changes (1995-2012).

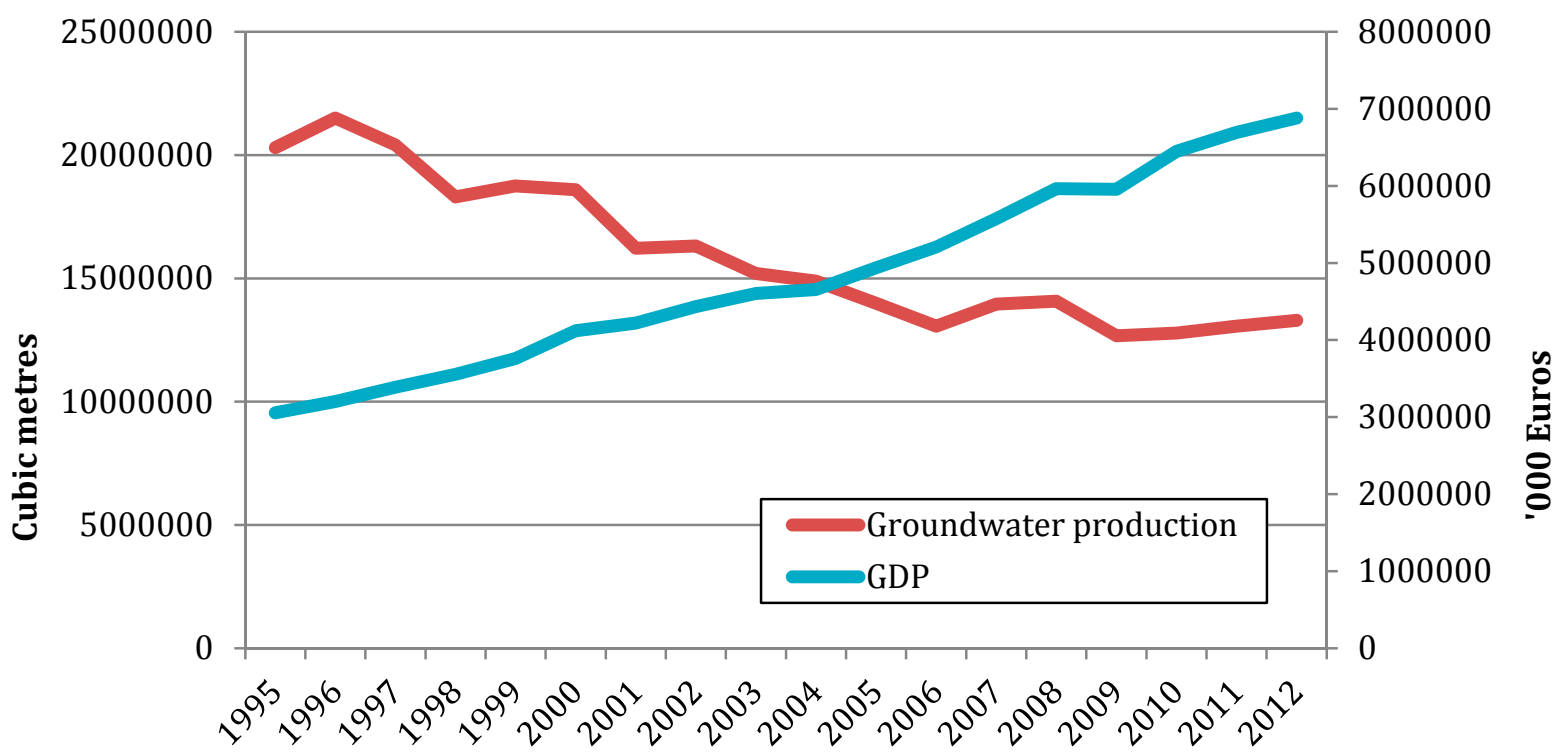

(a)

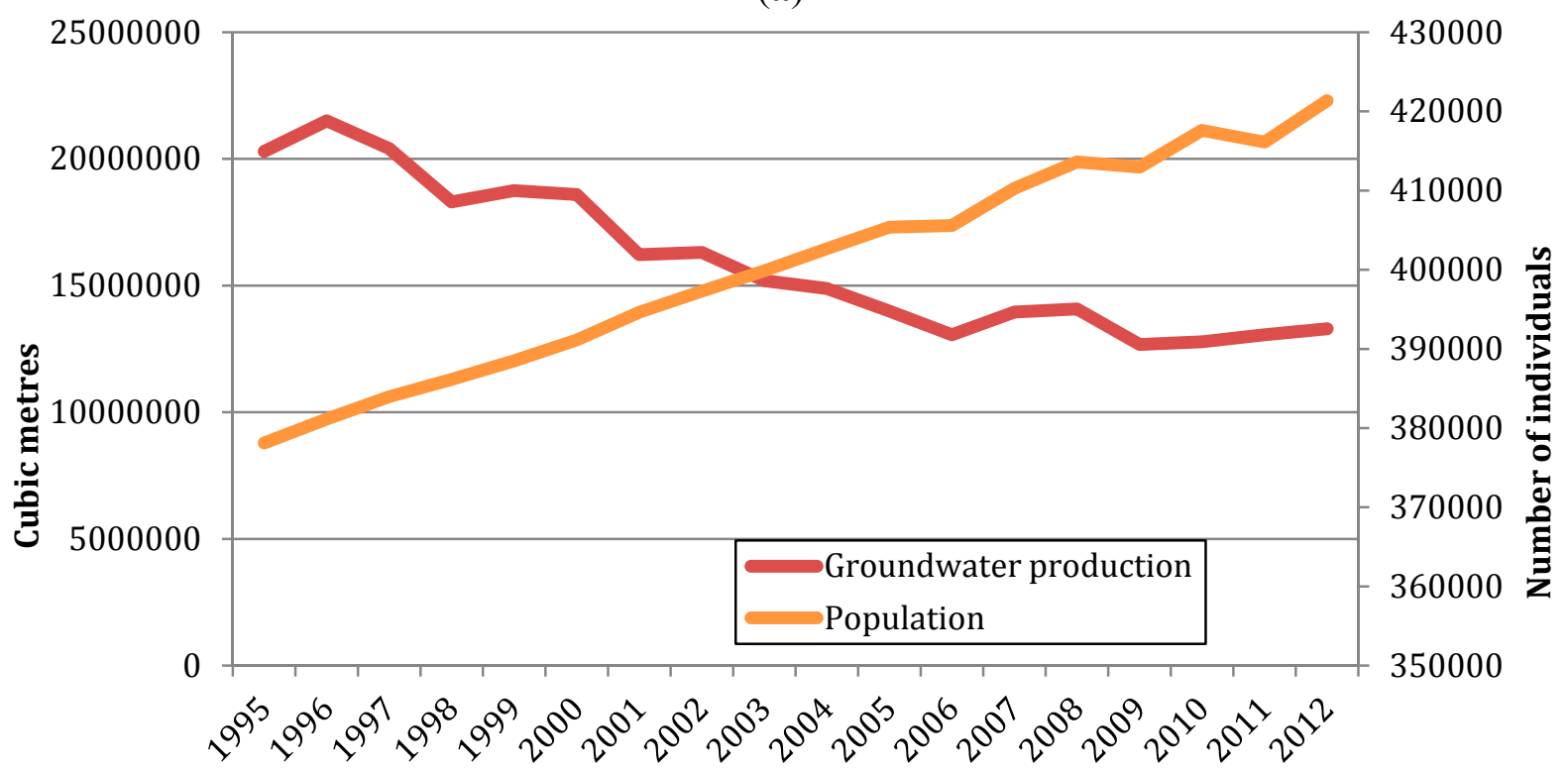

(b)

\subsubsection{Water Production from Desalination Plants per Unit of GDP and per Capita}

Absolute decoupling of water production from GDP and population growth appears to have occurred over the period of analysis 1995-2012, during which water production through desalination 
decreased by a significant $44 \%$, notwithstanding growth in both GDP and population (Figure 5). The relevant decoupling factors per GDP and per capita are 0.75 and 0.5, respectively, marginally larger than the corresponding DFs for groundwater abstraction. These high DFs are at least in part due to large-scale infrastructural works to reduce leakage losses from the underground water distribution network, with these possibly distorting the extent to which these values truly reflect dematerialization, or the "detachment" of economic growth from intensity of water use. Indeed, notwithstanding these high values, negative DFs (i.e., increasing EP) were recorded between 2010-2012, with water production increasing (by 10\%) over this time-frame. For accurate assessment of decoupling in this case, one would therefore need to consider the time period following the upgrading of infrastructure, to remove the distortion introduced by this aspect.

Figure 5. (a) Changes in production of desalinated water vs. GDP changes (1995-2012) (top); (b) changes in production of desalinated water $v$ s. population changes (1995-2012).

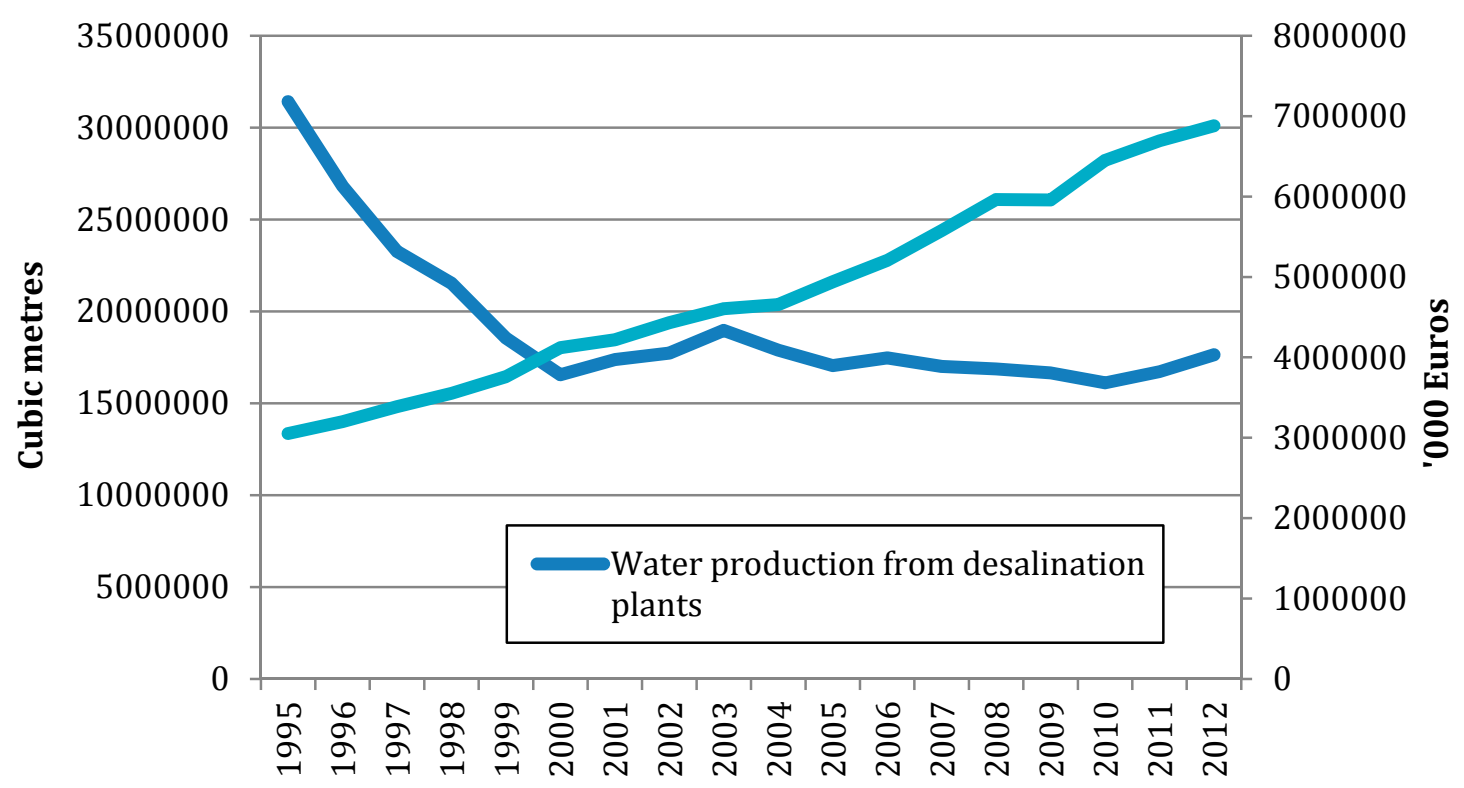

(a)

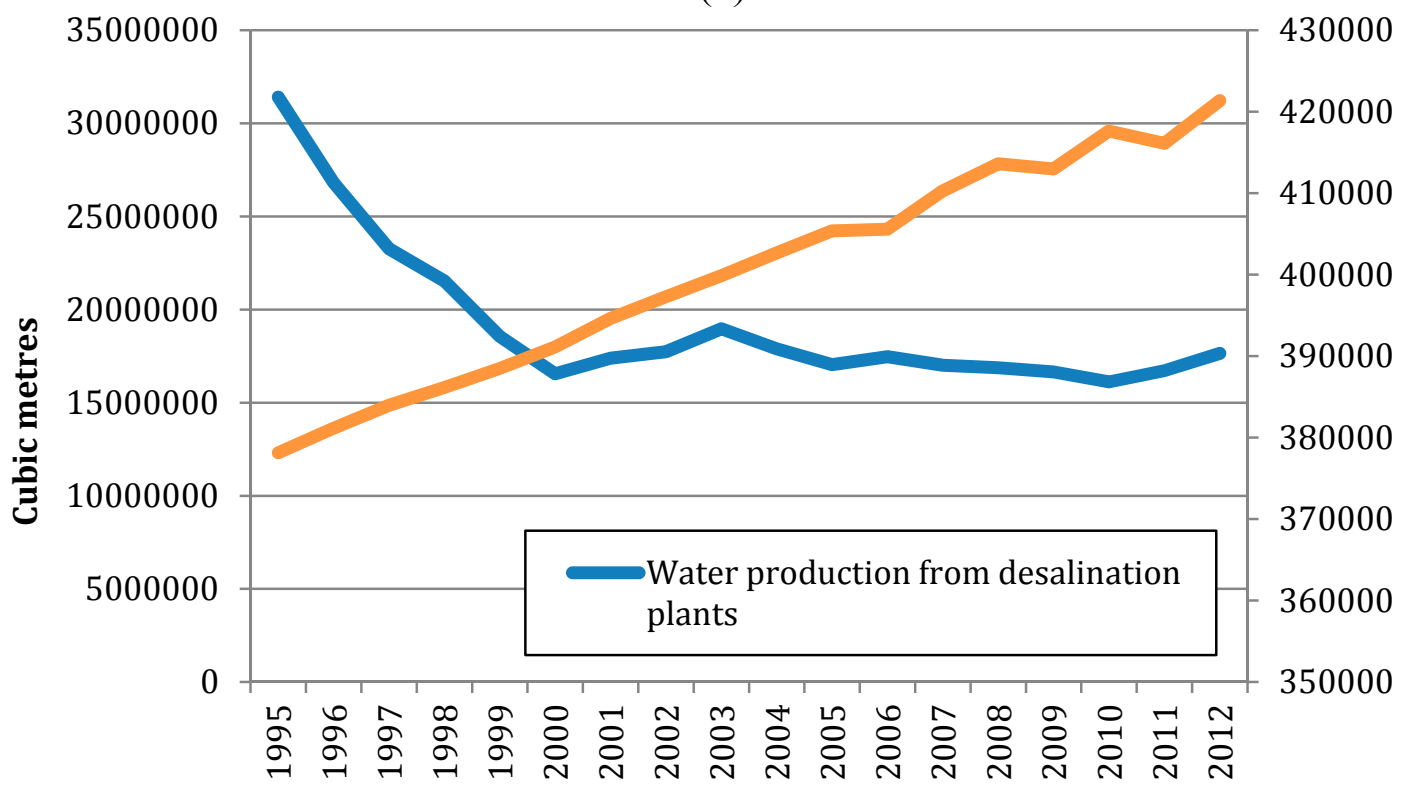

(b) 


\subsection{Waste}

When Malta acceded to the EU in 2004, waste was an environmental sector characterized by under-performance; as a result, specific (more lenient) targets were negotiated for the country [71]. Key waste management issues at the time included strong reliance on landfilling as a disposal method, inadequate sewage treatment, and a fragmented legislative framework. Since then, the country has made significant efforts to adopt a more holistic waste management approach, with the most recent Waste Management Plan adopted in 2014. Key targets include reducing the amount of waste going to landfill, increased recycling, and more extensive recovery of construction and demolition waste [72].

Waste-related indicators listed in the OECD report were (i) municipal waste going to final disposal versus private final consumption (PFC); and (ii) amount of glass not collected for consumption versus PFC. For purposes of this study and based on available data, we considered (i) the total amount of waste managed per unit of GDP and per capita; (ii) the proportion of total waste managed comprised of MSW; and (iii) the proportion of total waste managed comprised of inert waste. The latter is a significant waste stream within the country, largely due to a large construction industry. Given that Malta now treats all sewage prior to discharge at sea, liquid waste indicators were not included as a distinct category. Relevant data was obtained from NSO statistics [73].

\subsubsection{Total Waste Managed per Unit of GDP and per Capita}

The amount of total waste managed decreased by $24 \%$ over the period of analysis (2005-2012), indicating decoupling of waste generation from increasing GDP and population (Figure 6). The DF for waste managed per unit of GDP has an overall value of 0.46 , with a corresponding value per capita of 0.27. While the overall downward trend in waste generation would seem to indicate that absolute decoupling may be taking place, annual data indicates differently; although a sharp decrease in waste management occurred in 2009, increases were registered in 2010 and 2012, suggesting the necessity of caution when interpreting data, until decreasing trends can be shown to be sustained over an extended time period.

Figure 6. (a) Changes in the amount of waste treated/managed vs. GDP changes (2005-2012) (top); (b) changes in production of desalinated water $v s$. population changes (2005-2012).

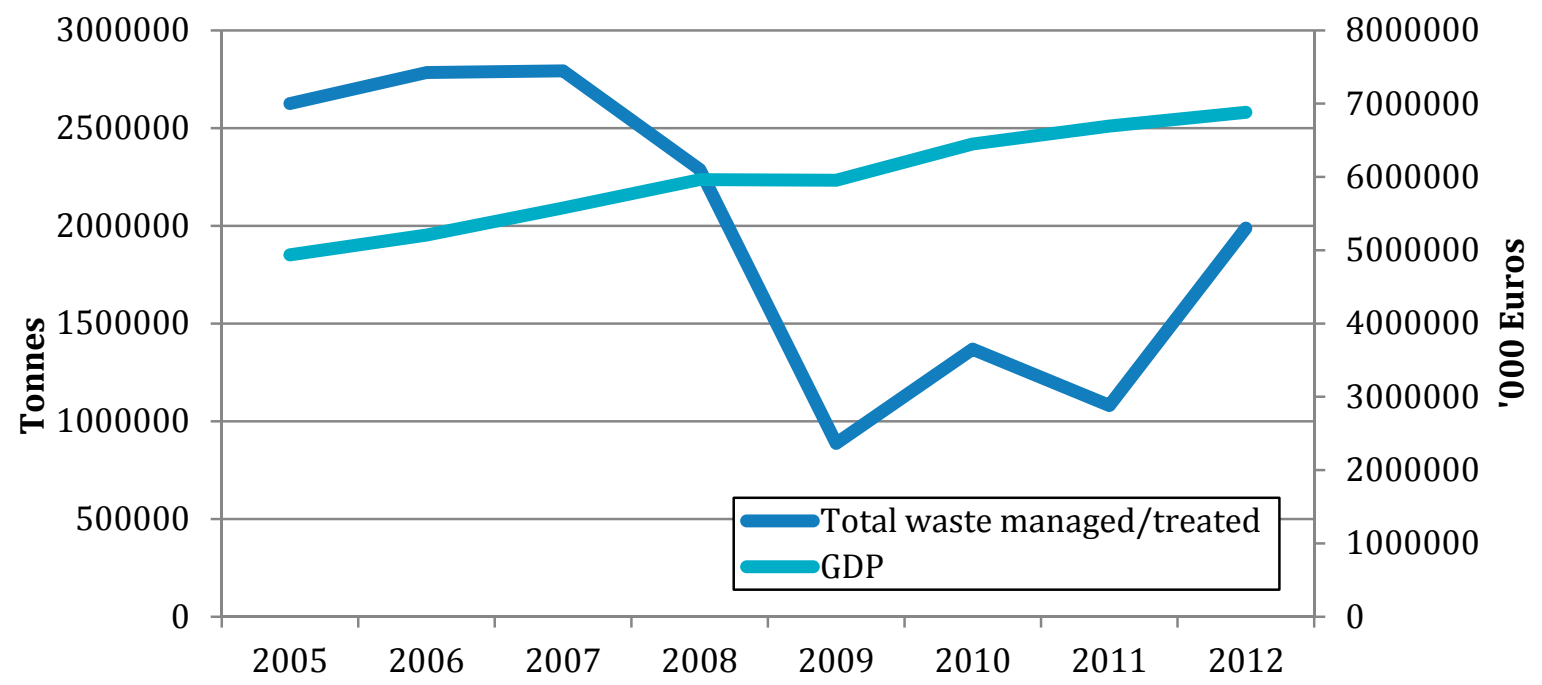

(a) 
Figure 6. Cont.

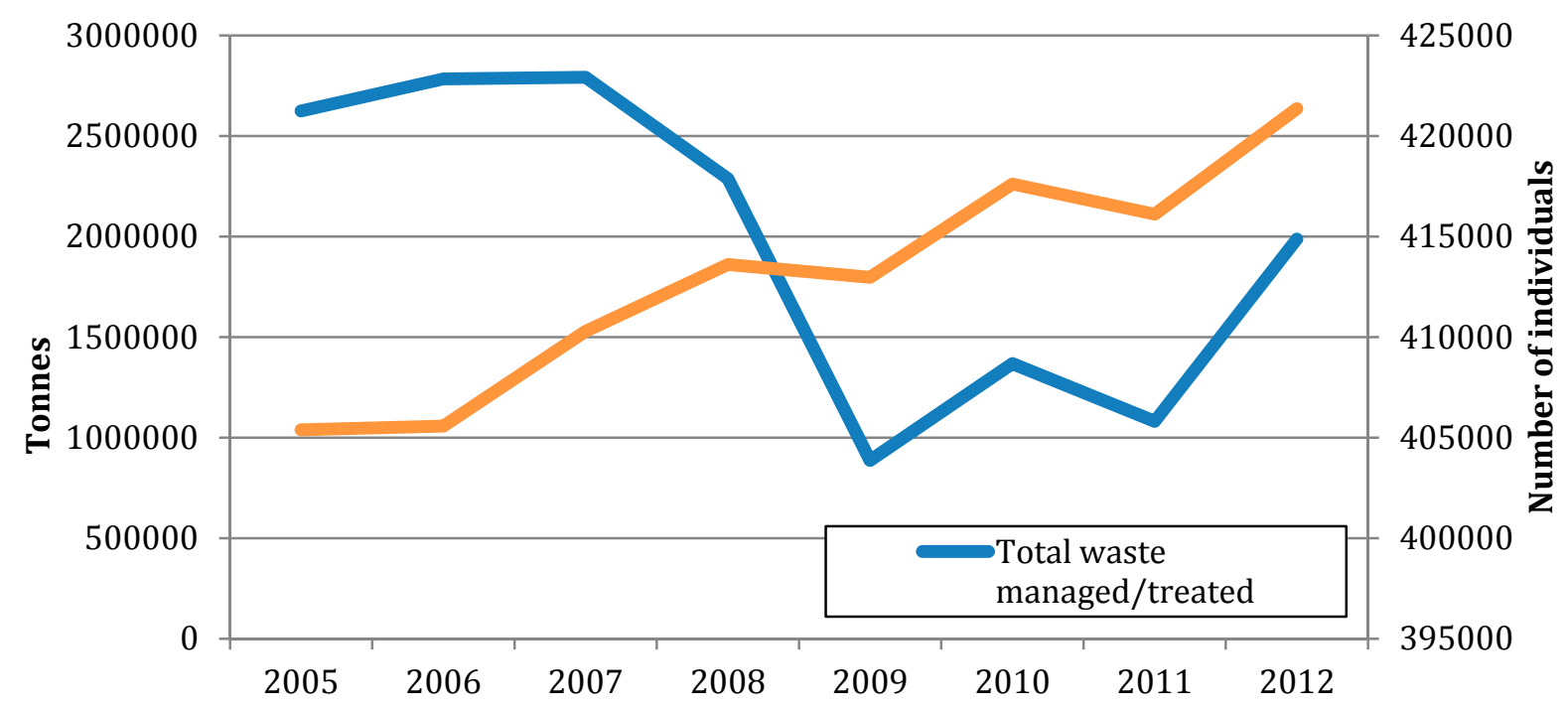

(b)

\subsubsection{Total Municipal Waste/Inert Waste per Unit of GDP and per Capita}

The generation of municipal waste decreased by 2\% between 2005 and 2012, although various inter-annual increases were recorded. The DF for municipal waste per unit of GDP is positive (0.3), indicative of decoupling, although it would probably be premature to describe this decoupling as absolute, given the absence of a clear long-term trend. Only a weak degree of decoupling seems to have occurred on a per capita basis (DF of 0.06), suggesting that the production of municipal waste from households remains significant. Stronger declines were registered in the generation of inert waste, with an overall decrease of $32 \%$ over the same period of analysis. While both inert waste per unit GDP and inert waste per capita were characterized by inter-annual variations, with negative DF values in several years, overall DF values were positive in both cases ( 0.52 and 0.35 , respectively). The results appear to indicate relative decoupling of both municipal and inert waste generation from GDP and population, respectively. While the OECD indicator of waste going to final disposal is not fully comparable and itself has issues of robustness, there is some similarity between the EPs it seeks to represent and the EPs resulting from municipal waste generation in this study. The OECD survey recorded relative decoupling for the most part, with absolute decoupling in several European countries. Malta has undoubtedly made progress in reducing municipal waste generation, but is still some way behind achieving the absolute decoupling already recorded in these European mainland countries.

\subsection{Land}

Land is a major limiting factor in a small island state; Malta, with a land area of only $316 \mathrm{~km}^{2}$, faces extreme competition for land and consequently a major environmental challenge in successfully retaining expanses of natural or semi-natural land for important ecosystem functions. Indeed, environmental discourses in the country in recent decades have been dominated by widespread criticism of what is often perceived to be unbridled urbanization [74]. While the OECD suite of indicators did not consider land as a resource in its own right, focusing instead on the resources that 
land provides, in a small island context land is a significant concern. While long-term land use statistics for Malta are limited, we here consider the land area affected by development as a "surrogate" indicator for threat to habitat and ecosystem integrity, given the lack of long-term data about the state of health of species and ecosystems. The indicator can also provide an indication of pressure on the land resource in general, not only in terms of the natural resources it contains, but also in terms of spread of urbanization.

\section{Land Area Affected by Development per Unit of GDP and per Capita}

There is limited long-term data documenting changes in land-use in Malta; it is unfortunate that given Malta's small size, broad-scale land-cover assessment methodologies (e.g., the CORINE methodology) widely in use across larger territories are limited in their ability to generate useful country-specific information. In this study, we were therefore constrained by lack of data, but nevertheless made use of available statistics from the Malta Environment and Planning Authority for 2000 and 2005 [75]; we also compiled a comparable estimate of land affected by development for the year 2006, based on data compiled through a Europe-wide project [76].

Land affected by development increased by $18 \%$ over these years, with the DF per unit of GDP close to zero (0.003). Given that the GDP growth rate is higher $(26 \%)$, some relative decoupling can be assumed to have taken place, although this is evidently limited. The DF per capita, on the other hand, is negative $(-0.05)$, indicating that no decoupling of land development from population growth has occurred; indeed, population increased by only $4 \%$ over the analysis time period, 14 percentage points less than the corresponding rate of increase in land affected by development.

\section{Conclusions}

The results above indicate significant progress in decoupling on some fronts, lesser progress on others, and no progress at all in one instance (Figure 7). The results obtained are indicative of a country that has made progress towards remedying environmental degradation, but that the pace of progress has varied across EPs. The unfortunate lack of long-term data does not permit a comprehensive long-term analysis of change in the country; however, this indicative review does suggest that caution should be exercised when referring to data summarizing change over an extended time period. In several instances, EPs were found to have decreased overall, but a closer look at interannual changes then revealed that this was not a result of a consistent trend; for example, a net positive DF could be derived from individuals "bursts" of progress occurring at intervals, but with increases in EPs registered during other (including more recent) years. It is also possible that significant progress over short intervals may not be indicative of sustainable decoupling but may rather reflect the immediate benefits of investments into improved infrastructure and governance (as for example, in the case of efforts to reduce leakage losses through the water distribution network). As noted earlier, Malta has a relatively young history of environmental management and planning, and as a result, its institutional and governance capacities are still evolving-for this reason, a longer period of analysis may be needed before such data can be considered to fully reflect the country's strategic development paths. It should also be noted that the analysis of decoupling is reflective of relative rather than absolute change; the absolute decoupling recorded for $\mathrm{SO}_{2}$ emissions, for example, does not take into 
account the fact that, notwithstanding positive progress, Malta is still some way from achieving its GP 2020 targets for this pollutant [77]. It is also of note that in all instances, decoupling of EPs from economic growth was more significant than decoupling from population growth, perhaps pointing to the significance of population pressures within small land areas, be these small island states, cities, or other densely populated environments. The absence of any decoupling of land development from population growth likewise suggests that some characteristic small island state pressures are highly significant.

Figure 7. Summary of decoupling factors for the indicators considered. A DF between 0 and 1 indicates that decoupling is occurring; a DF between 0 and -1 is indicative of no decoupling.

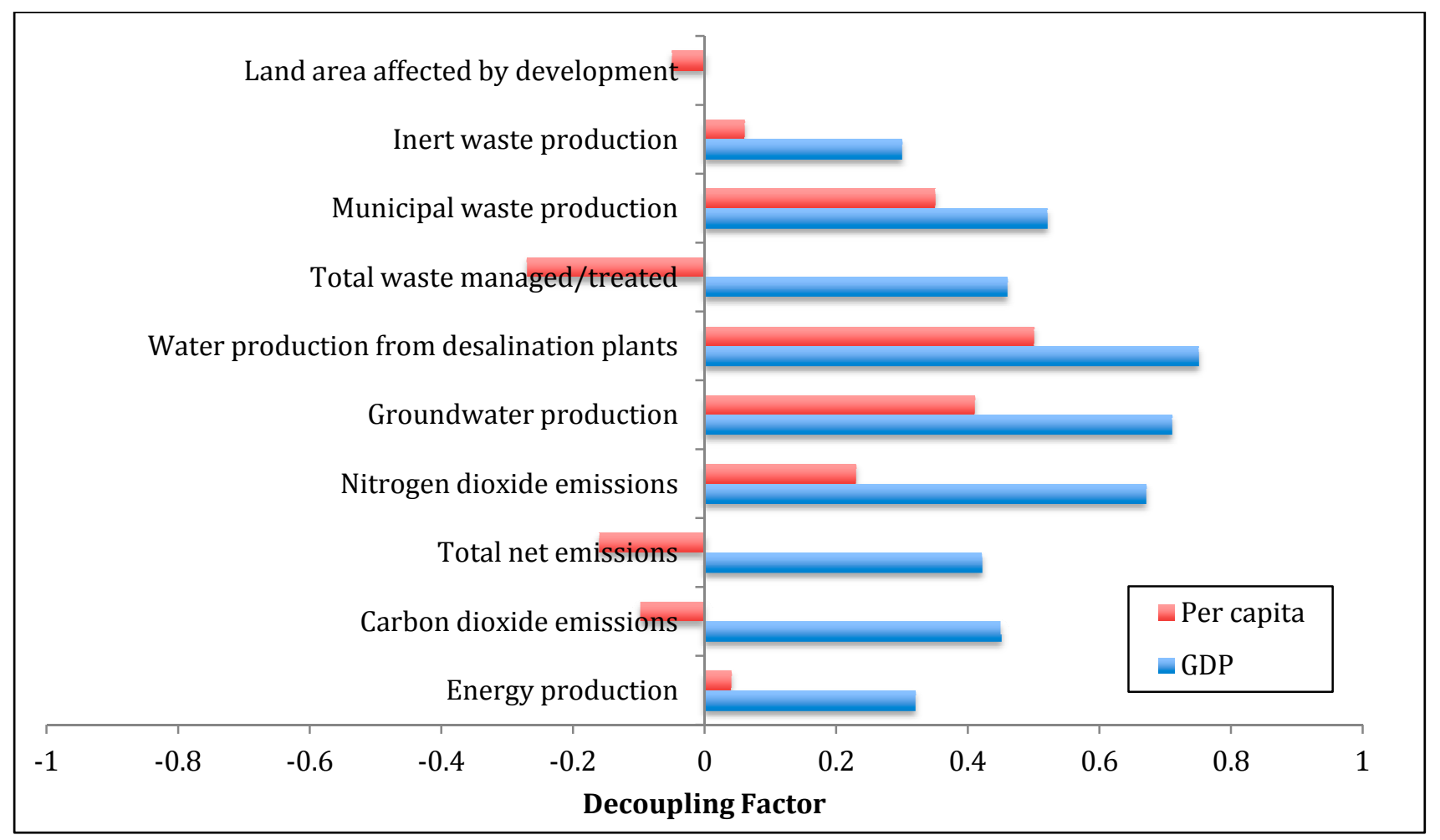

What additional insights can be derived from this case study? First, it raises a note of caution with regard to the way in which decoupling analyses may claim to analyze environmental degradation. As noted above, several analyses of environment-economy decoupling are based on a single indicator (as noted above, often related to carbon emissions or energy use); while these analyses are perfectly valid, it is important to bear in mind that there are many more facets to environmental degradation beyond climate change. At the relatively small-scale level of an island state or city, some of these environmental facets may indeed be more immediately and critically relevant to economic and social well-being, and a positive "report card" for a single indicator, such as carbon emissions, may disguise significant environmental degradation in other spheres - the water situation in the island state of Malta is a case in point. If decoupling is indeed to be considered a measure of sustainability, then it needs to factor in environmental degradation at more than just the global scale, and needs to be able to account for a variety of indicators of environmental "pressure" and "state" at local level, including aspects of environmental pressure that may be challenging in terms of measurement (for example, relating to 
pressures on ecosystem services). Second, the case study points to the importance of developing methodologies that are able to account for environmental degradation "hidden" in imports and exports; Malta, like several other island contexts, is heavily dependent on imports of resources (both actual and virtual), and the results presented here are therefore limited in the extent to which they fully reflect the environmental impact of a country and its people. The point is also valid for city contexts, which are likewise embedded within a flow of goods and services, and is arguably valid for most economies, even larger ones. While greenhouse gas emissions accounting allows for distinctions to be drawn between production-based and consumption-based emissions, measures of decoupling are otherwise still rather limited in their ability to account for the geographical displacement of environmental impacts, again rendering decoupling results somewhat misrepresentative. In this regard, a good model is provided by various sector-specific methodologies that focus on the entire life-cycle of a resource, such as water footprint accounting. A third conclusion that can be drawn relates to the particularities of the development trajectories of different countries or regions; this analysis of a single small-island state shows how data features can often be explained by extraneous factors that are not generally analyzed within decoupling studies, even ones using advanced numerical multivariate techniques which, by their very nature, require a generic approach. Results discussed above highlight the danger of misinterpreting data which may be "distorted" by factors such as one-off capital investment projects (for example, in the case of efforts to improve water infrastructure), political developments (for example, accession to the European Union), data classification systems (for example, in the case of land use data), or simply the absence of data to allow analysis of an issue of environmental concern (for example, nitrate pollution). This would suggest that, at smaller scales, qualitative analysis may also have a role to play in a fair and accurate assessment of the environment-economy relationship. This has already been alluded to in some of the literature; for example, Jorgenson and Burns outline the importance of conducted more nuanced empirical assessments of the environmental commitments of nation states and the extent to which such commitments tangibly reduce different forms of environmental degradation [9].

\section{Acknowledgments}

The authors are grateful to Stephanie Vella (University of Malta) for guidance concerning the use of Malta's GDP data.

\section{Author Contributions}

Elisabeth Conrad was responsible for data compilation; both authors contributed to data analysis and to the drafting of the manuscript.

\section{Conflicts of Interest}

The authors declare no conflict of interest.

\section{References and Notes}

1. Kuznets, S. Economic growth and income inequality. Am. Econ. Rev. 1955, 45, 1-28. 
2. He, J.; Richard, P. Environmental Kuznets Curve for $\mathrm{CO}_{2}$ in Canada. Ecol. Econ. 2010, 69, 1083-1093.

3. Lee, C.; Chiu, Y.; Sun, C. The Environmental Kuznets Curve Hypothesis for Water Pollution: Do Regions Matter? Energy Policy 2010, 38, 12-23.

4. Leitão, A. Corruption and the Environmental Kuznets Curve: Empirical Evidence for Sulfur. Ecol. Econ. 2010, 69, 2191-2201.

5. Sephton, P.; Mann, J. Further Evidence of an Environmental Kuznets Curve in Spain. Energy Econ. 2013, 36, 177-181.

6. Harbaugh, W.T.; Levinson, A.; Wilson, D.M. Reexamining the Empirical Evidence for an Environmental Kuznets Curve. Rev. Econ. Stat. 2002, 84, 541-551.

7. Caviglia-Harris, J.L.; Chambers, D.; Kahn, J.R. Taking the "U" Out of Kuznets: A Comprehensive Analysis of the EKC and Environmental Degradation. Ecol. Econ. 2009, 68, 1149-1159.

8. Mills Busa, J.H. Dynamite in the EKC Tunnel? Inconsistencies in Resource Stock Analysis under the Environmental Kuznets Curve Hypothesis. Ecol. Econ. 2013, 94, 116-126. Rev. Econ. Stat. 2002, 84, 541-551.

9. Jorgenson, A.K.; Burns, T.J. The Political-Economic Causes of Change in the Ecological Footprints of Nations, 1991-2001: A Quantitative Investigation. Soc. Sci. Res. 2007, 36, 834-853.

10. Stern, D.I. The Rise and Fall of the Environmental Kuznets Curve. World Dev. 2004, 32, 1419-1439.

11. Rockstrom, J.; Steffen, W.; Noone, K.; Persson, A.; Chapin, F.S., III; Lambin, E.; Lenton, T.M.; Scheffer, M.; Folke, C.; Schellnhuber, H.; et al. Planetary boundaries: Exploring the safe operating space for humanity. Ecol. Soc. 2009, 14, 32.

12. Steffen, W.; Rockstrom, J.; Costanza, R. How Defining Planetary Boundaries Can Transform Our Approach to Growth. Available online: http://www.thesolutionsjournal.com/node/935 (accessed on 5 September 2014).

13. Baykan, B.G. From limits to growth to degrowth within French green politics. Environ. Polit. 2007, 16, 513-517.

14. Priesnitz, W. It's Not about Growth. Nat. Life 2009, 126, 62.

15. Van der Voet, E.; van Oers, L.; Nikolic, I. Dematerialization: Not just a Matter of Weight. J. Ind. Ecol. 2004, 8, 121-137.

16. Van Caneghem, J.; Block, C.; van Hooste, H.; Vandecasteele, C. Eco-Efficiency Trends of the Flemish Industry: Decoupling of Environmental Impact from Economic Growth. J. Clean. Prod. 2010, 18, 1349-1357.

17. Verfaillie, H.A.; Bidwell, R. Measuring Eco-Efficiency-A Guide to Reporting Company Performance. Available online: http://oldwww.wbcsd.org/web/publications/measuring_eco_efficiency.pdf (accessed on 1 August 2014).

18. Van der Voet, E.; van Oers, L.; Moll, S.; Schutz, H.; Bringezu, S.; de Bruyn, S.; Sevenster, M.; Warringa, G. Policy Review on Decoupling: Development of Indicators to Assess Decoupling of Economic Development and Environmental Pressure in the EU-25 and AC-3 Countries. Available online: http://ec.europa.eu/environment/natres/pdf/fin_rep_natres.pdf (accessed on 12 September 2014). 
19. UNEP. Decoupling Natural Resource use and Environmental Impacts from Economic Growth. Available online: http://www.unep.org/resourcepanel/decoupling/files/pdf/decoupling_report_ english.pdf (accessed on 3 June 2014).

20. Haberl, H.; Fischer-Kowalski, M.; Krausmann, F.; Weisz, H.; Winiwarter, V. Progress towards Sustainability? What the Conceptual Framework of Material and Energy Flow Accounting (MEFA) can offer. Land Use Policy 2004, 21, 199-213.

21. Knight, K.W.; Rosa, E.A.; Schor, J.B. Could Working Less Reduce Pressures on the Environment? A Cross-National Panel Analysis of OECD Countries, 1970-2007. Global Environ. Change 2013, 23, 691-700.

22. Steinberger, J.K.; Roberts, J.T.; Peters, G. How Much is Enough? A Sufficiency Perspective on Low-Carbon Development Pathways. Available online: http://www.ukerc.ac.uk/support/tiki-download_ file.php?fileId=1966\&display (accessed on 1 August 2014).

23. Giljum, S.; Behrens, A.; Hinterberger, F.; Lutz, C.; Meyer, B. Modelling Scenarios towards a Sustainable use of Natural Resources in Europe. Environ. Sci. Policy 2008, 11, 204-216.

24. Huppes, G.; Ishikawa, M. Eco-Efficiency Guiding Micro-Level Actions towards Sustainability: Ten Basic Steps for Analysis. Ecol. Econ. 2009, 68, 1687-1700.

25. Wursthorn, S.; Poganietz, W.; Schebek, L. Economic-environmental Monitoring Indicators for European Countries: A Disaggregated Sector-Based Approach for Monitoring Eco-Efficiency. Ecol. Econ. 2011, 70, 487-496.

26. Jevons, W.S. Of the economy of fuel. Org. Environ. 2001, doi:10.1177/1086026601141006.

27. York, R. Ecological Paradoxes: William Stanley Jevons and the Paperless Office. Res. Hum. Ecol. 2006, 13, 143-147.

28. Binswanger, M. Technological Progress and Sustainable Development: What about the Rebound Effect? Ecol. Econ. 2001, 36, 119-132.

29. York, R.; Rosa, E.A. Key Challenges to Ecological Modernization Theory. Org. Environ. 2003, 16, 273-288.

30. Calwell, C. Is Efficient Sufficient? The Case for Shifting Our Emphasis in Energy Specifications to Progress Efficiency and Sufficiency. Available online: http://www.eceee.org/policy-areas/ sufficiency/eceee_Progressive_Efficiency.pdf (accessed on 1 August 2014).

31. Daly, H.E. Towards a Steady-State Economy; W.H. Freeman \& Co. Ltd.: San Francisco, CA, USA, 1973.

32. Schumacher, E.F. Small is Beautiful; Harper \& Row: New York, NY, USA, 1973.

33. Gorgescu-Roegen, N. The Entropy Law and the Economic Process; Harvard University Press: Cambridge, MA, USA, 1971.

34. Daly, H.E. Beyond Growth: The Economics of Sustainable Development; Beacon Press: Boston, MA, USA, 1996.

35. Van den Bergh, J.C.J.M. Environment Versus Growth—A Criticism of "degrowth" and a Plea for “a-Growth". Ecol. Econ. 2011, 70, 881-890.

36. Kallis, G. In Defence of Degrowth. Ecol. Econ. 2011, 70, 873-880.

37. Latouche, S. Farewell to Growth; Polity: Cambridge, UK, 2010. 
38. Steinberger, J.K.; Krausmann, F.; Getzner, M.; Schandl, H.; West, J. Development and Dematerialization: An International Study. Development and Dematerialization: An International Study. PLoS One 2013, doi:10.1371/journal.pone.00703858.

39. Krausmann, F.; Fischer-Kowalski, M.; Schandl, H.; Eisenmerger, N. The Global Socio-Metabolic Transition: Past and Present Metabolic Profiles and their Future Trajectories. J. Ind. Ecol. 2008, $12,637-656$.

40. Steinberger, J.K.; Krausmann, F.; Eisenmenger, N. Global Patterns of Material use: A Socio-Economic and Geophysical Analysis. Ecol. Econ. 2010, 69, 1148-1158.

41. Jorgenson, A.K.; Clark, B. Societies consuming nature: A panel study of the ecological footprints of nations, 1960-2003. Soc. Sci. Res. 2010, 40, 226-244.

42. Ru, X.; Chen, S.; Dong, H. An Empirical Study on Relationship between Economic Growth and Carbon Emissions Based on Decoupling Theory. J. Sustain. Dev. 2012, 5, 43-51.

43. Mattila, T. Any Sustainable Decoupling in the Finnish Economy? A Comparison of the Pathways and Sensitivities of GDP and Ecological Footprint 2002-2005. Ecol. Ind. 2012, 16, 128-134.

44. Andreoni, V.; Galmarini, S. Decoupling Economic Growth from Carbon Dioxide Emissions: A Decomposition Analysis of Italian Energy Consumption. Energy 2012, 44, 682-691.

45. Bertram, G.; Poirine, B. Island political economy. In A World of Islands; Baldacchino, G., Ed.; Agenda Academic \& Institute of Island Studies: Luqa, Malta \& Charlottetown, PE, Canada, 2007; pp. 323-378.

46. Baldacchino, G. Development strategies for smaller island states and territories: An ecological approach. In Landscape Approaches for Ecosystem Management in Mediterranean Islands; Conrad, E., Cassar, L.F., Eds.; Institute of Earth Systems, University of Malta: Msida, Malta, 2012; pp. 31-44.

47. Storey, D. Kiribati: An environmental "perfect storm”. Aust. Geogr. 2010, 41, 167-181.

48. Fathimath, G. Sustainable development in small island developing states. Environ. Dev. Sustain. 2003, 5, 139-165.

49. Taylor, J. Saving small island developing states: environmental and natural resource challenges 2012, 7, 149-150.

50. Lane, D.; Mercer Clarke, C.; Forbes, D.; Watson, P. The Gathering Storm: Managing adaptation to environmental change in coastal communities and small islands. Sustain. Sci. 2013, 8, 469-489.

51. Tapio, P. Towards a Theory of Decoupling: Degrees of Decoupling in the EU and the Case of Road Traffic in Finland between 1970 and 2001. Transp. Policy 2005, 12, 137-151.

52. Wang, W.; Kuang, Y.; Huang, N.; Daiqing, Z. Empirical Research on Decoupling Relationship between Energy-Related Carbon Emission and Economic Growth in Guangdong Province Based on Extended Kaya Identity. Sci. World J. 2014, Article ID 782750.

53. OECD. Indicators to Measure Decoupling of Environmental Pressure from Economic Growth. SG/SD(2002)1/FINAL. Available online: http://www.oecd.org/officialdocuments/ publicdisplaydocumentpdf/?cote=sg/sd(2002)1/final\&doclanguage=en (accessed on 3 June 2014).

54. Ehrlich, P., Holdren, J. The impact of population growth. Science 1971, 171, 1212-1217.

55. Dietz, T., Rosa, E.A. Rethinking the environmental impacts of population, affluence, and technology. Hum. Ecol. Rev. 1994, 1, 277-300. 
56. York, R.; Rosa, E.A.; Dietz, T. STIRPAT, IPAT and ImPACT: Analytic Tools for Unpacking the Driving Forces of Environmental Impacts. Ecol. Econ. 2003, 46, 351-365.

57. Norden (Nordic Council of Ministers). Measuring Sustainability and Decoupling: A Survey of Methodology and Practice; Nordic Council of Ministers: Copenhagen, Denmark, 2006.

58. National Statistics Office (NSO-Malta). Environment Statistics. Available online: http://www.nso.gov.mt/statdoc/document_view.aspx?id=57\&backurl=/themes/theme_page.aspx (accessed on 12 September 2014).

59. Eurostat. News Release: Renewable Energy in the EU28. 37/2014. Available online: http://epp.eurostat.ec.europa.eu/cache/ITY_PUBLIC/8-10032014-AP/EN/8-10032014-AP-EN.PDF (accessed on 12 September 2014).

60. Galdies, C. The Climate of Malta: Statistics, Trends, and Analysis 1951-2010. Available online: http://www.nso.gov.mt/statdoc/document_file.aspx?id=3141 (accessed on 12 September 2014).

61. World Health Organization. Environment and Health Performance Review: Malta. Available online: http://www.euro.who.int/_data/assets/pdf_file/0006/95343/E93547.pdf (accessed on 12 September 2014).

62. NSO. Energy Consumption in Malta: 2003-2012. Available online: http://www.nso.gov.mt/ statdoc/document_view.aspx?id=3622 (accessed on 12 September 2014).

63. De Freitas, L.C.; Kaneko, S. Decomposing the Decoupling of $\mathrm{CO}_{2}$ Emissions and Economic Growth in Brazil. Ecol. Econ. 2011, 70, 1459-1469.

64. Vehmas, J. Decomposition Analysis of $\mathrm{CO}_{2}$ Emissions from Fuel Combustion in Selected Countries. Int. J. Environ. Technol. Manag. 2009, 11, 47-67.

65. Malta Resources Authority. National Greenhouse Gas Emissions Inventory for Malta 2013-Annual Report for Submission under the United Nations Framework Convention on Climate Change. Available online: https://unfccc.int/national_reports/annex_i_ghg_inventories/national_ inventories_submissions/items/7383.php (accessed on 1 September 2014).

66. Cremona, M.; Saliba, G. Water Consumption Benchmarks: A Step Towards Reduced Consumption. Available online: http://ec.europa.eu/environment/life/project/Projects/index.cfm?fuseaction= home.showFile\&rep=file\&fil=InvestingInWater_Paper_May2012FINAL.pdf (accessed on 12 September 2014).

67. Mangion, J.; Micallef, P.; Attard, G. Treated sewage effluent: an alternative water supply for the Maltese Islands. In Options Méditerranéennes: Série B. Etudes Et Recherches; Hamdy, A., El Gamal, F., Lamaddalena, N., Bogliotti, C., Guellobi, R., Eds.; CIHEAM/EU DG Research: Bari, Italy, 2005.

68. National Statistics Office (NSO-Malta). News Release: World Water Day 2014. Available online: http://www.nso.gov.mt/statdoc/document_file.aspx?id=3974 (accessed on 12 September 2014).

69. Cremona, E. University of Malta, Msida, Malta. 2014, unpublished work.

70. National Statistics Office (NSO-Malta). News Release: World Water Day 2013. Available online: http://www.nso.gov.mt/statdoc/document_file.aspx?id=3556 (accessed on 12 September 2014).

71. Axiak, V.; Gauci, V.; Mallia, A.; Mallia, E.; Schembri, P.J.; Vella, A.J.; Vella, L. State of the Environment Report for Malta 2002; Malta Environment and Planning Authority: Floriana, Malta, 2002. 
72. Ministry for Sustainable Development, the Environment and Climate Change. Waste Management Plan for the Maltese Islands: A Resource Management Approach 2014-2020. Available online: http://msdec.gov.mt/en/Document\%20Repository/Waste\%20Management\%20Plan\%202014\%20\%202020\%20-\%20Final\%20Document.pdf (accessed on 12 September 2014).

73. National Statistics Office (NSO-Malta). Solid Waste Management in Malta: 2012. Available online: http://www.nso.gov.mt/statdoc/document_view.aspx?id=3683 (accessed on 12 September 2014).

74. Cassar, L.F. A Landscape Approach to Conservation: Integrating Ecological Sciences and Participatory Methods; Institute of Earth Systems, University of Malta: Msida, Malta, 2010.

75. National Statistics Office (NSO-Malta). Sustainable development indicators for Malta 2010. Available online: http://www.nso.gov.mt/statdoc/document_view.aspx?id=2848 (accessed on 12 September 2014).

76. European Environment Agency. Land use-State and Impacts (Malta). Available online: http://www.eea.europa.eu/soer/countries/mt/land-use-state-and-impacts-malta (accessed on 12 September 2014).

77. European Environment Agency. Air Pollution Fact Sheet 2013: Malta; European Environment Agency: Copenhagen, Denmark.

(C) 2014 by the authors; licensee MDPI, Basel, Switzerland. This article is an open access article distributed under the terms and conditions of the Creative Commons Attribution license (http://creativecommons.org/licenses/by/4.0/). 